\title{
Development impacts of value chain interventions: how to collect credible evidence and draw valid conclusions in impact evaluations?
}

\author{
Giel Ton, Sietze Vellema and Marieke de Ruyter de Wildt \\ LEI, Wageningen University and Research Centre, Hollandseweg 1, 6706 KN Wageningen, the Netherlands; giel.ton@wur.nl
}

\begin{abstract}
In development policy and practice, support to or interventions in value chains are considered to be instrumental for achieving outcomes such as poverty alleviation. This paper reviews methodological discussions on how to show the effects and workings of value chain support in a context of donors demanding rigorous impact evaluations. The paper starts with a discussion of evaluation methods strongly anchored in ex-post statistical analysis of effect measurements, and argues in favour of a theory-based evaluation protocol, equipped to handle threats to valid conclusions. Value chains are open, multilayered systems and development outcomes are multi-dimensional and contingent on contextual particularities. Moreover, development interventions in value chains are often time, place and commodity specific and unlikely to be repeated in a similar way, which complicates generalisation and constrains evaluative conclusions. The example of a small-grant fund promoting collective marketing by smallholder organisations illustrates these methodology challenges and shows the value of using a mix of methods for addressing the problems of outcome measuring, impact attribution and generalisations from highly diverse contexts.
\end{abstract}

Keywords: rural development, mixed methods, attribution, organisational performance, realist evaluation

\section{Introduction}

Value chain development has emerged as an important area of donor interventions for poverty reduction in developing countries. The World Development Report 2008 (World Bank, 2007) considered it as a centrepiece of agricultural policy in developing countries. Value chain support focuses on capacities and capabilities of value chain actors and the enabling policies and institutions that facilitate change processes that benefit the poor. Donor interventions link actor-specific effects, such as increased incomes for farmers, to overall performance of a specific value chain. Chain performance can be enhanced by policies and projects that, for example, increase the scale of operations, improve service provision to producers, develop capacities to comply with (buyer-driven) quality requirements or address the process of value creation and value distribution. This also makes value chain development or support container concepts that have strong parallels with generic policy approaches such as 'private sector development' (Donor Committee for Enterprise Development), 'making markets work for the poor' (DFID), 'growing inclusive markets' (UNDP), and 'opportunities for the majority' (IADB).

The discussion in this paper is motivated by the growing public pressures on development cooperation and aid money to show its worth; convincing evidence is expected for the effect on poverty alleviation (DAC, 2008). These calls for credible evidence have led to more stringent accountability requirements for agencies, making it mandatory for them to defend the logic and demonstrate the impact of these interventions (Tanburn, 2008). However, generating convincing evidence on the link between development outcomes and donor-supported value chain interventions is not easy.

Value chains are complex, multi-layered and open sociotechnical systems that are influenced by a myriad of intervening actors, and are continuously shaped and reshaped to adapt to changing conditions. A whole range of unintended consequences of value chain support are difficult to grasp; and, there is the critique that value chain support picks 'winners' by focusing on a relatively small group of entrepreneurial poor and hence has a limited impact on average poverty levels (Humphrey and NavasAleman, 2009).

Development outcomes are also dependent on the ways in which value chains touch down in specific contexts wherein governments, business associations, entrepreneurs, producers' organisations and/or labour unions negotiate rules and institutions that shape development outcomes (Helmsing and Vellema, 2011). Attribution of impacts of interventions in this dynamic 'cloud' of evolving and intertwined sets of institutional arrangements is difficult, though necessary to answer legitimate questions on relevance, effectiveness and replicability of value chain support (DAC, 2008; Roche and Roche, 1999). 
One of the promising initiatives to generate credible and comparable information on donor-funded value chain interventions originates from the Donor Committee for Enterprise Development (DCED, 2010). The initiative proposes a set of minimum standards for reporting on private sector development outcomes. When fully implemented, this could result in a body of evidence on plausible regularities resulting from value chain support, which lends itself for comparative analysis and benchmarking (Maredia, 2009). The argument developed in this paper shares the interest of DCED in measuring outcomes of an explicit intervention logic, but warns against a one-sided emphasis on measuring effects, and against a tendency to constrain the design of impact evaluations to one-method econometrics. We stress that a methodological design has to face the most common threats to validity to the evaluative conclusion (Bamberger et al., 2006; Creevey and Woller, 2006; Shadish et al., 2002).

The paper consists of three sections. First, we discuss the basic ingredients of impact evaluations, namely the questions asked and conclusions drawn, and illustrate the different threats to validity when concluding on evaluative questions. Second, we examine in more detail the methodological challenges for measuring outcome patterns, attributing outcomes in open systems, and generalizing conclusions from diverse pilot experiences. Third, we illustrate the points raised with a real impact evaluation assignment of an intervention supporting collective marketing activities by farmers' organisations active in a wide range of different value chains and social contexts. In the conclusions, we stress the importance of linking ex-post impact evaluation processes with ex-ante constructions of plausible impact theories and credible outcome measurement methods.

\section{Impact evaluations: credible evidence and valid conclusions}

There are many different reasons for doing an evaluation. Chelimsky and Shadish (1997) distinguish three types of evaluations: those that primarily look for accountability, for knowledge, or for development. Accountability evaluations look at the value of public expenditures, focusing on issues of costs, efficiency and effectiveness; knowledge evaluations aim for insights into problems, policies, programmes and processes, analysing old interventions in order to develop new ones; and development evaluations seek to strengthen institutions and agencies in a particular evaluative area. The first two types are largely summative in nature, while the third type is largely formative. We focus in this paper especially on the first two types of evaluations, which are directed toward measuring and attributing outcomes of interventions. This section examines two key aspects of such impact evaluations, what type of questions to start with, and how to end up with answers that can face critical scrutiny.

\section{Asking evaluative questions}

Summative impact evaluations address varying combinations of three basic questions for which information and evidence has to be collected:

- Does it work? What positive and negative changes did the intervention generate in the performance of the value chain?

- How does it work? What components of the support generated intended or unintended effects, for whom, and under what conditions?

- Will it work elsewhere? What components might work for whom under what conditions?

The first question is a quest for evidence of effects and is especially relevant when public or private investments have alternatives and need an indication of the extent to which their support contributed to stated objectives. The second one is especially directed to the processes that make this happen: the generative mechanisms (Gerring, 2008). Thirdly, an impact evaluation is often commissioned to assess the possibilities to replicate an intervention in other contexts, or upscale it from 'pilot' to 'mainstream'. This third question is more directly related to the policy recommendations of an evaluation; often the best read part of any evaluation report and the most vulnerable to critique. Each evaluation assignment will build upon a combination of these three basic questions. The 'weight' of each type of question is decided at the start of the assignment. The first and third questions get generally more attention than the second, the 'How does it work?' question, and this has major impacts on the research methodologies preferred. We share the observation by Pawson and Tilley (1997) that the first question is far too dominant in evaluation research whilst the second question is more productive in providing guidance to stakeholders and in generating useful policy recommendations. Also Ravallion (2009), chief evaluator at the World Bank, points to the dominance of evaluation assignments that limit themselves to show whether policies work or not, without generating additional information on how they work and could work in other settings. He opposes, specifically, the dominance of econometric impact assessment methods that only compare average values of indicators between treated and control groups. According to Ravallion (2009), echoing similar concerns by Heckman and Smith (1995), the audience of most impact assessments, policy makers, also want to know whether the intervention worked in the way it was intended to work, whether it worked the same for different groups, whether it still worked 
after the programme was scaled up, and whether it can work differently.

The above presents one of the challenges central to this paper: how to arrive at an appropriate combination of evaluation questions with a proper research design to measure outcome patterns, gain insight into the inner workings of the interventions and gain an appreciation of the social embedding of impacts. The three questions require different kinds of information, or, at least, information with different 'depth and detail'. Whereas the first question may treat the intervention as a one-package black box, the second question explicitly opens the black box to know what generative mechanisms are fired, or not. Information relevant for the second question documents processes, sequences of instructive events, time paths and outcome patterns differentiated for distinct groups or areas. The answer to the third question builds on the data and conclusions of the first two questions and needs information on the circumstantial conditions enabling or constraining these processes.

\section{Drawing valid conclusions}

Above we argued that any evaluative assignment has to arrive at an appropriate combination of three questions. The answers to these questions need to be robust and be able to address the most obvious threats to validity. Shadish et al. (2002) argue that no generalised causal inference has absolute validity; there will always be some specific conditions that limit the generalisation domain of the conclusion. They stress the need to design procedures that (partially) control some of the limitations of the research methods used that may weaken the validity claims of causal inferences. However, in many evaluations the validity issue is only applied to the tools and techniques used, not to any systematic assessment of validity threats on the conclusions. In this paper, we acknowledge that most impact evaluations have to make pragmatic choices related to budget, time and data (or sometimes political) constraints. Focusing attention on how one can still draw valid conclusions on the basis of available evidence seems therefore timely (Bamberger, 2007). Few evaluations in international development systematically address issues of validity; the field of value chain support is no exception to this (Humphrey and NavasAleman, 2009; Zandniapur et al., 2004).

We consider it useful to adopt the four threats to valid conclusions proposed by Shadish et al. (2002):

- Statistical conclusion validity: the way inferences about correlations are made in data-set observations. This emphasises the need to comply with proven methods to estimate association or correlation between variables.
- Internal validity: the way causality is attributed in the evaluation. This refers to the logic behind the observed correlations and explains why and how interventions contribute to the observed change.

- Construct validity: the way that generalisations are made from the categories used in the evaluation to broader units of representation. This stresses the importance of precise definitions and concepts.

- External validity: the way that the findings are generalizable to other persons, times and contexts. This requires being precise about conditions and requirements that define the generalisation domain.

Statistical conclusion validity involves statistical analysis of data-sets, usually comparing groups of respondents and calculating averages or other measures of comparison in the sample population. Several tests help to conclude on the probability or 'significance' of a correlation between their characteristics and the outcomes. Just producing an output table that indicates 'significant' relations is insufficient. All statistical tests have assumptions and pre-conditions related to the data, like the 'normal distribution of the data' or the 'homogeneity of variance of the different groups'. Taking statistical conclusion validity seriously, we need to be explicit about such assumptions, and include analytical methods to check these assumptions.

Internal validity is intimately related to the argumentations to support a causal inference. It is important to be clear about how the evaluative research makes the link between an intervention (cause) and specific outcomes in the value chain. There are three basic conditions that define causality (Mill, 2009 (1843)): the cause needs to be active before the effect is produced; the cause must be related to the effect produced; and alternative explanations of the effect must be discarded. In value chain development, it is unlikely that there is just one cause of the change. More likely it is configurational: several joint influences are necessary for producing the observed outcomes (Blatter and Blume, 2008). Each individual factor in a configuration is a socalled inus condition: in itself insufficient to explain the outcomes of a support intervention, but a non-redundant part of a wider constellation of factors that is unnecessary but sufficient to produce the outcome (Mackie, 1965). For attributing outcomes to an intervention, hence, we will have to make plausible that the value chain support was indeed a necessary ingredient of the configuration of factors that produced the observed change in outcomes. Non-observables, characteristics or factors that are not (and often cannot be) registered in the data-set, may provide for alternative explanations of the observed effects. Strong evaluative conclusions, therefore, need to collect information on a wide range of factors that might 
be important. To support an evaluative conclusion on the effectiveness of a value chain support intervention, the non-redundancy of the intervention in this constellation of causal factors will have to be made plausible.

Construct validity is about whether we indeed collect information about categories and concepts used in the research design. The evaluators need to be explicit about the way they generalise the concepts and constructs that they use in the evaluation. For example, if we conclude something about the effectiveness of a certain intervention in the chain, e.g. 'investments in cooling tanks makes linkages of dairy producers to markets more remunerative', we immediately face several threats to construct validity. Is 'dairy producers' a good construct, or do we need to make distinctions in small and bigger dairy farmers, diversified farms or specialized farms? Does the inference hold for all types of investment support that facilitate cooling tanks in this specific case, or do we need to make distinctions in grants and credit schemes, or farmer-driven and government-driven schemes? Is it valid for all markets, or only for the urban fresh milk markets and not for cheese and yoghurt markets? To face threats to construct validity, we need to be precise about the concepts and constructs used and design our research methods accordingly.

Even more challenging are the threats to external validity. When we come to the conclusion that in a specific context the intervention was a key factor with positive results, this will not necessarily hold in all other settings. Hence, we need to clarify why, and to what extent, the outcomes came about in this specific situation and whether the findings can be generalised and remain valid for other contexts and conditions. All 'best practices' and lessons learnt on value support can be questioned by indicating a 'peculiarity' related to the context. For example, the outcomes of what seems to be a technical intervention in a value chain, such as setting up a warehouse, can be dependent on the nature of collective action among farmers or on the articulation of farmer groups with business association and local government departments in a context of decentralisation. In this section, we discussed that impact evaluations require capacity to combine three different questions and to address four threats to drawing valid conclusions. Below, we will examine such a combinatory framework that is linked to collecting evidence informing how we define, describe and defend our 'generalisation domain' (Chen, 1994).

\section{Methodology challenges}

We will now apply these validity checks to three methodology challenges that are core in evaluation research on value chain dynamics and that intimately relate with the evaluation questions: Does it work? How does it work? and
Will it work elsewhere? Our first concern is the problem of measuring outcome patterns. Performance indicators vary from relatively simple indicators to complex constructs that are difficult to operationalise. Second, we focus on the issue of attribution. In complex and multi-layered social systems like value chains, no intervention functions in isolation: many stakeholders, prices and market trends influence value chains that are socially embedded in diverse cultural settings. Moreover, interventions have various components, implemented with different time frames, in varying combinations that interact with each other. We complement this with a third challenge: how to generate generalisable conclusions on the possible replication of interventions that are socially embedded in quite distinct contexts and conditions.

\section{Measuring outcome patterns}

The first evaluation question, Does it work?, seeks to measure the change caused by the intervention. The DCED (2010) proposes some basic steps for this: define the impact model; define indicators of change (and projections); measure these indicators; and capture the wider change in the value chain. In value chains, support is often directed at actors and institutions in the environment of (poor) producers, like financial and non-financial business support services, rather than at producers themselves. All interventions will have an explicit or implicit 'theory of change' or impact model on how the support is expected to translate into desired outcomes related to these service providers and institutions, and on how these changes are expected to generate better incentives for producers in the value chain. This impact model helps to focus the evaluation on key assumptions in the logic. The evaluation is not necessarily comprehensive but, indeed, may better concentrate on 'critical' subsets of conditions, components of interventions, specific instruments and types of outcome patterns that are expected to be present/working (Maredia, 2009).

In designing the concepts and indicators in impact assessments, construct validity is a key challenge. Performance of a value chain relates to different layers and dimensions of social interaction in the chain network. Similar to the challenges in assessing other abstract attributes of social systems, like 'organisational strength', the immaterial aspect of chain performance makes it difficult to capture and measure. Moreover, concepts and indicators to assess performance are often influenced by the disciplinary background, ontological theories and personal interests of the evaluator (Vellema, 2011). For example, when looking for outcomes of support to multi-stakeholder chain platforms, an economist trained in transaction economics will look for 'trust' and 'coordination' between 
chain actors, while someone specialised in the analysis of group dynamics will focus on 'inclusion/exclusion' and 'synergy'. A political economist will see 'changing power relations' and a scholar in strategic marketing will look at 'innovativeness' and 'competitiveness'. All will see some of the outcomes of the intervention, but not the whole picture. It is, therefore, important to carefully select indicators and select an evaluation team and research methodology that is able to identify and operationalise the relevant performance indicators (Snodgrass, 2006), where triangulation of different sources of information and metrics helps to better frame changes in value chain performance (Denzin, 1970), and multiple ways of approaching may help to identify causal factors, inus conditions, that explain their realisation (Blaikie, 1991).

Even apparently straightforward indicators need to be well defined, according to a causal model that is comprehensive enough to include the most important outcomes, but lean enough to facilitate attribution. One of the three 'universal' indicators proposed by DCED (2010) is 'additional net income (additional sales minus additional costs) accrued to targeted enterprises as a result of the programme per year'. This sounds straightforward; however, the scope for varying interpretations is considerable. For example, net additional income as a result of a dairy development intervention can be restricted to net income growth from fresh milk sales. However, it can also be understood as the net income change of the whole agricultural system of the household, as increasing dairy production and increased animal feed production may impact horticultural production and family income. Positive spill-over effects may exist too, since farmers may have learned about milk quality issues, and, as a result of increased communication with other chain actors, may have improved their entrepreneurial skills and technology beyond diary only. However, this more comprehensive way of calculating net income introduces a wider range of confounding factors that complicate the attribution of the impact to the specific intervention: e.g. horticultural prices fluctuate a lot between weeks and seasons and are prone to natural conditions, and will influence incomes without any causal relation with the dairy support intervention being evaluated.

\section{Measuring accurately}

Commonly, changes in value chain performance are assessed by subtracting or comparing indicator scores: at least a 'before-after' situation and, if possible, a 'withwithout' estimate. Measuring differences in indicator scores with some accuracy is more important than measuring the absolute value of the indicator. Relatively small measurement errors in both indicators may translate into large errors in the calculated difference between them. Tracing these measurement errors in indicator averages between non-equivalent groups is difficult and often limited to outlier checks only. For example, differences in income calculations from the same respondents in consecutive surveys can be influenced by recall bias or other critical estimation errors (Ton et al., 2010). Too often researchers analyse data that has not been checked sufficiently for data collection errors (Vaessen, 2010). Careful outlier elimination often improves the analysis lot. However, routine outlier eliminations can have adverse results. While the reasons for these outliers can indeed be related to data collection or data transcription, and elimination from the data-set is then an improvement, some outliers may well reflect real situations and be very useful for understanding the change processes and enabling conditions related to the interventions, e.g. for analysing 'contrasting cases' (Lawson, 2009; Rihoux and Ragin, 2008). Eliminating these outliers reduces the information in and usefulness of the data-set..

To indicate the impact that is attributable to interventions, a comparison is needed with a fictive situation in which the intervention had not been active (Khandker et al., 2009). Ideally, this would be a group with similar characteristics that did not experience the working of the interventions. The comparison between these two groups helps to assess whether the outcomes can be attributed to any 'exogenous' or 'unknown' causal factor, not related to the intervention's causal mechanisms. Experimental methods, with random assignment to treatment and control groups (Duflo et al., 2006) are especially designed to facilitate this measurement of outcomes between treated and non-treated groups. However, this design is often impossible (Bamberger et al., 2006; Shadish et al., 2002) and deliberate exclusion of some groups of stakeholders in the value chain from the benefits of a support intervention (like coordination platforms, value chain financing, certification programmes, investment subsidies) is often socially and politically unfeasible. Also, in many cases, there are important spill-over effects from pilot-intervention areas to other areas and the definition of who is a participant and who is not is a gliding scale, making the distinction between 'treated' and 'control' groups unworkable (Ravallion, 2009). Random assignment of the intervention to a defined population is rarely possible and, therefore, other, quasi-experimental methods are more frequently used. However, research designs that deviate from random assignment face the risk of being affected by a selection bias, introducing differences between the treatment and the control group that are unrelated to the intervention, but important in producing the outcomes (attitude, resource base, etc.). This is a major threat to the validity of the statistical conclusion. A proper evaluation 
design will have to consider, limit and control for such a bias in data-set observations.

Generally, a survey produces a set of qualitatively distinct variables used as proxies for 'improved livelihood strategies of smallholder households'. Statistical analysis, with a set of distinct dependant outcome variables, generates additional threats to validity of the correlations found. Current software makes consecutive iterations of statistical analysis with changing combinations of variables so easy that 'significant' correlation between variables may result from 'fishing the data': repeating statistical tests that analyse the significance of differences between groups by selectively re-grouping respondents, variables, etc. Even if the intervention has no effect at all, in complex data sets one or more significant correlations are likely to appear after a sufficient number of iterations (Shadish et al., 2002).

Concluding on causal relations from such correlations may wrongly attribute these outcomes to the intervention. On the one hand, conclusions tend to concentrate primarily on significant effects, which results in a bias in impact evaluations towards 'significant' though irrelevant conclusions. On the other hand, non-significant effects can be a result of low statistical power (low sample size) or measurement errors that could have been corrected when more deeply analysed. Large mean effects need attention even when they do not prove statistically significant.

A recommended solution against 'fishing' is to specify, exante, the hypothesised mechanisms or theoretical model that is tested and to increase the threshold (significance level) of the correlation detected through iterative analysis. However, fishing is difficult to detect as often no exante causal hypothesis exists. Or, more commonly, the hypothesis is adjusted during analysis and reporting the data. Interestingly, this temptation is even stronger for academics involved in evaluative research, as the chance of research results being published in scientific journals is far higher with an argument that is supported with 'significant' statistical evidence, especially when sample sizes are low (Begg, 1994). This 'publication bias' creates incentives for ex-post modelling of hypotheses and generates a problem for meta-research, as there is an overestimation of changes as a causal result of interventions in the literature.

Only data-set observations from surveys with a sufficient sample size (statistical power) will make it possible to detect differences between subgroups in the survey population. Commonly, a minimum subgroup size of 30 is used as a rule-of-thumb (Creevey and Ndiaye, 2008). The sample size will have to consider attrition: some respondents will fall out of the sample due to moving, passing away or changing activities. When one wants to compare different subgroup locations $(g)$ disaggregated on typology criteria $(c)$, this minimum total sample size will, thus, be, roughly, $N=$
$30^{*} g^{*} \mathrm{c}$. For explorative statistical analysis, and considering attrition, sample sizes are ideally larger than the minimal required size. In the 'real world', however, sample sizes are often restricted by resource constraints (insufficient financial means, limited number of available subjects, difficult-toreach locations, etc.).

The DCED recommends capturing wider changes than just 'predicted' change by the logical model or intervention theory. The most obvious threat to validity of an evaluative conclusion is that it leaves important factors out of the equation, be they confounding causal factors or outcome indicators, thereby weakening the internal validity of the findings. Unintended outcomes are not likely to be captured by pre-established indicators derived from causal impact models, and unexpected though important context-specific characteristics might not be captured by research tools that collect information on factors related to the intervention theory only. Additionally, more open and qualitative CausalProcess Observations (Brady et al., 2006) are needed to check for these unintended outcomes. The emphasis on documenting wider impacts is important; too often, evaluations restrict assessment designs to find proof for impact logic only (European Commission, 2008).

\section{Attribution in open systems}

Data-set observations need causal theories to differentiate between co-linearity (changes happen together) and causality. Detecting the inner workings of the processes underlying theobserved changes is necessary to interpret observed correlations and to identify causal relations. Significant correlations do not indicate causality, but at least indicate that there is, probably, a relation between the intervention and the outcomes. This holds especially for relatively simple or moderately complicated systems (Rogers, 2009; Snowden and Boone, 2007). However, this is far less realistic for interventions with a wide constellation of causes in systems that behave with increasing levels of complexity (Hospes, 2008; Lawson, 2003; Pawson, 2002; Snowden and Boone, 2007). If value chain support takes place with a high degree of contingency in system behaviour, which is usually the case, experimental and quasi-experimental methods that rely on data-set regressions alone will have problems in the internal validity of their conclusions (Heckman, 2005). The difficulty in grasping the complexity of a change process in econometric models holds also for the popular evaluation research designs based on comparing groups through 'matching' procedures, like Propensity Score Matching (PSM). In PSM, impact is assessed by measuring the outcome difference in pairs of respondents that 'match' on most of their characteristics, except their adoption of the innovations promoted by the intervention. The characteristics on which 
matching takes place are, ideally, derived from a model that comprises the whole 'constellation of factors' that are expected to lead to the measured outcomes (e.g. adoption of technology that leads to higher income levels). The matching is done through calculation of a 'propensity score' for all respondents on a construct of different variables that 'models' the context of the respondent. The respondents with a comparable score on the model's dimensions will form 'matched pairs' and are supposed to share the likelihood to have the same outcomes, except the ones that result from the adoption of the innovation promoted by the support intervention. The difference in outcomes between the 'matching pairs' of adopters and the non-adopters are considered to be attributable to the intervention.

As will be clear from the above, these matching models are heavily theory laden, and they suppose that the matching is done on all relevant variables that will make the pairs react similarly to the interventions. This model to 'capture context' is ideally elaborated before the PSM survey data is gathered (because the survey needs to produce information on all the characteristic). However, in practice, it is often only constructed after the survey, during data-analysis, and the matching model is constrained to only those variables that are readily available in the data-set for both beneficiaries and non-beneficiaries. But even when the data collection is comprehensive, in complex systems, the model used to match respondents will always be incomplete and will suffer from 'essential heterogeneity' (Heckman, 2005): it may miss a latent, unobserved external factor that is key in the constellation of causal factors that determine the outcomes for stakeholders of the interventions. Even the more sophisticated econometric methods that explicitly try to correct for the variance due to unobservable factors will end up testing closed models of reality. Therefore, critics may always challenge the validity claims of causal inferences derived from econometric analysis of survey data, indicating that the model is too simplistic and that the context is far too complex to be captured in mathematical models (Lawson, 2003). A (partial) defence against these critics is to limit PSM to only those social processes that are relatively simple. Social systems with increased levels of complexity or chaos limit the possibility to generate credible and valid conclusions with quasi-experimental research designs (Maredia, 2009) and, hence, need a more appropriate mix of methods.

Following from the above, we think that more explicit, ex-ante theorisation is beneficial for rigorous impact evaluation. The workings of the intervention are often implicitly assumed and not explicated in an impact logic, or intervention theory. For the purpose of focussing impact evaluations on key assumptions in the intervention logic, Chen (1994) makes a useful distinction in two sets of intervention theories: causal theories and normative theories of programme impact. Causal theories are descriptive of change processes in social systems, while normative theories are more prescriptive and action oriented and represent the causal assumptions in the impact model of an intervention. Obviously, the latter benefits from the first and normative theories improve when more causal theory is generated.

Realist evaluation (Pawson and Tilley, 1997) provides a useful framework for detecting mechanisms or causal steps to which change or effect can be attributed. Pawson and Tilley propose a process of configurational and contextual thinking about how outcomes are brought about. They consider passing through a series of iterative circles between theory testing, i.e. on plausible explanations of a change process, and data collection and data analysis as a necessary step for detecting specific mechanisms in an intervention that may be 'fired' in a specific context and that trigger behavioural and institutional change. They emphasise the need to build ex-ante hypotheses related to the (project) mechanisms that (are assumed to) motivate or influence stakeholders 'to act differently' and generate changes in outcomes. Pawson and Tilley propose to test key assumptions in these hypotheses by using a Context-Mechanism-Outcome (CMO) configuration. The realist concept of 'mechanisms' opens the black-box between intervention/treatment and outcome/impact. The concept 'configuration' indicates that mechanisms will only produce certain outcomes in certain contexts, and results in key discriminations that automatically limit the generalisation domain of the causal inference. In contrast to the mainstream econometric approaches, realist evaluators concentrate on the 'treatment' and the different configuration of behavioural incentives for the 'treated', without bothering too much about a control group.

In evaluations of value chain support interventions, the realist framework can be used to describe the workings of interventions in context. Table 1 presents the elements of such a framework, highlighting the incentives that motivate the different chain actors in agricultural value chains. The detailed description and analysis of a (series of) pilot intervention may than provide the framework for a new intervention theory in new policies, and the research results may feed into learning processes on good principles or practices in value chain development.

Critics of realist evaluation point to the tendency to generate a whole range of hypotheses from qualitative case studies that cannot be tested with the available empirical evidence. 'It is undoubtedly desirable to test theories about causal mechanisms underlying the effect of an intervention on an outcome. The main problem is that numerous hypotheses can be formulated, and it is difficult to collect adequate data to test many of them.' (Farrington, 2003: 66). Farrington 
Table 1. A 'realist' case study format for value chain research.

\begin{tabular}{|c|c|c|}
\hline & \multicolumn{2}{|l|}{ Domain of application } \\
\hline & Causal theories & Normative theories \\
\hline Aim & Understanding pilot interventions & Designing policy and programme \\
\hline Context & $\begin{array}{l}\text { Situation of relevant value chain stakeholders in } \\
\text { the pilot experience }\end{array}$ & $\begin{array}{l}\text { Situation of the relevant value chain } \\
\text { stakeholders in another setting where the } \\
\text { support intervention will take place }\end{array}$ \\
\hline Mechanism & $\begin{array}{l}\text { Incentives that condition the behaviour } \\
\text { of stakeholders in specific institutional } \\
\text { arrangements that have emerged in and around } \\
\text { the value chain }\end{array}$ & $\begin{array}{l}\text { Intervention that changes the incentive } \\
\text { structure for stakeholders and generates an } \\
\text { improved institutional arrangement in and } \\
\text { around the value chain }\end{array}$ \\
\hline Outcome & $\begin{array}{l}\text { Actual performance of these institutional } \\
\text { arrangements in the value chain }\end{array}$ & $\begin{array}{l}\text { Intended outcomes of the intervention on } \\
\text { institutional arrangements }\end{array}$ \\
\hline CMO configurations & $\begin{array}{l}\text { Comparative case descriptions of causal } \\
\text { connections between interventions and } \\
\text { the performance of specific institutional } \\
\text { arrangements }\end{array}$ & $\begin{array}{l}\text { Defined recommendation domain for replicable } \\
\text { policies and interventions that enable } \\
\text { effective and sustainable institutional } \\
\text { arrangements in the value chain }\end{array}$ \\
\hline
\end{tabular}

argues that with limited time and resources for evaluations, it is difficult to deal with multiplicity of contexts, mechanisms and outcome patterns. He argues that qualitative research methods alone lack the necessary procedures to answer the most obvious threats to internal validity. He strongly favours the use of statistical analysis of data-set observations on exante hypothesis on the effectiveness of mechanisms.

We agree with Farrington that, when designing impact evaluation research, it is recommended to generate comparative data-set observations with a broad enough set of variables to verify the expected outcome patterns derived from plausible explanatory theories, which can be used to support the validity claim of inferences from the 'thicker' realist case studies. However, ex-post hypothesising remains important; a combination of 'deduction' and 'induction', or, in the realist tradition between 'interpretation' and 'abduction' (Blaikie, 2000), is key to make sense of the surprises, contingencies and dynamic changes that characterise most value chains. We might also disagree with him on the type of statistical analysis that can be applied on the resulting data-set to derive to meaningful conclusions on causality, where variable-based regression seems to be his golden standard (Lawson, 2003).

Recently, several new methods have been developed for statistical analysis of configurations of mechanisms, instead of discrete variables, that are active in each case study. Instead of econometric regressions that look for significant correlations between (groups of) cases based on their difference on discrete variables, they propose methods of classification that respect the integrity of each case as a system that can have different outcomes according to different sets of variables/factors. These 'Case-based Methods' (Byrne and Ragin, 2009) include diverse tools like cluster analysis, contrasting case methods and qualitative comparative analysis (Ragin, 2000, 2008; Rihoux and Ragin, 2008) and are promising as part of a mixed-methods evaluation design capable of configurational explanations.

\section{Generalisation on socially embedded interventions}

Threats to external validity arise when the conclusions of an evaluation are not bound to the population and/or context from which observations are made, e.g. a sample has been taken and is applied to contexts and conditions that are totally different in space and time. Unfortunately, this generalisation of conclusions to dissimilar contexts and conditions is often explicitly asked for when the evaluation of agricultural value chain support pilots are concerned. External validity of these generalised inferences might be threatened, as evidence of impact in one commodity chain will not necessarily be relevant for another commodity, and evidence in one setting or time period will not be generalisable to another. Policy makers are often especially interested in 'best practices', as it provides them with a menu of options. Evaluative conclusions to be used by policy makers, therefore, have to maximise the generalisation domain while maintaining validity and credibility. 'good practices', 'best fit solutions' or 'principles' are all concepts 
used to indicate mechanisms or interventions that proved to have worked in a certain setting, and that might work in others. Instead of strong causal inferences about 'best practices', only possible in relatively simple social change processes, the challenges discussed in this paper are more appropriate for the complicated and complex change processes observed in value chain interventions.

In this section, we discussed in more detail methods for collecting credible evidence on outcome patterns and for detecting candidate mechanisms. To maximise the generalisation domain of the conclusions on impact while respecting its limits, Shadish et al. (2002) present principles to check external validity of findings. Two of these are especially useful for comparative research on value support that wants to conclude on replicability: first, to assess the apparent similarities between the context of the intervention that has been studied and the characteristics of the context targeted for replication (Surface Similarity, and second, to explicate those contextual differences that are considered irrelevant for their conclusions on replicability (Ruling Out Irrelevancies). We consider this still as a relatively uncharted terrain, where less proven tools and methods are available. Nevertheless, to facilitate this type of generalisations on replicability, the format of realist case studies, explained above, seems helpful to generate comparative information on contexts and mechanisms that work in specific value chain support interventions.

\section{Application}

From the above, we can distil the main steps to get a rigorous methodological design for impact evaluation assignments of development interventions in agricultural value chains. For evaluations that intend to conclude on the replicability or scalability of agricultural value chain interventions, we propose a design that is based on a combination of (1) impact models that reflect the intervention theory; (2) a realist focus on the mechanisms that are assumed to be fired by the intervention and the conditions under which these work; and (3) triangulation of data-set observations and casual process observations with, case-based, comparative statistics. The resulting mix of data-collection methods provides useful information for accountability purposes, for monitoring on-going interventions and for learning on good principles and best-fit practices that have potential to be effective when replicated in future interventions.

We summarise the methodology challenges and the evaluative questions as described above in Table 2, in which ++ indicates the core challenges for a research design to provide answers on each of the questions. The challenge of attribution is vital to all rigorous evaluation assignments, with the measuring challenge and the generalisation issue as complementary challenges somewhat more related to the kind of question that is central. This difference in emphasis helps to select the core methodology, and can guide decisions to incorporate complementary methods by revising the validity threats to the expected type of conclusions to be derived from this core methodology. We illustrate this with an evaluation assignment on a dynamic change process in fifty different value chains contexts in Bolivia. It couples a pretty 'standard' donor intervention with high diversity in contexts and high diversity in generative mechanisms.

\section{FONDOECAS: a small-grant fund for collective marketing}

FONDOECAS is a semi-autonomous entity managing a small-grants programme that caters to economic smallholder associations. The small-grant fund finances investments in processing equipment and related capacity building to organised groups that have already been engaged in collective marketing activities for some years. The small grants amount to around US\$10,000 each. Between 2007 and 2010, FONDOECAS reached around ninety organisations, with an estimated total membership of 18,000 families.

We start with a reflection on the logic model and the evaluation questions that became central to the assignment, and show that this translates into high demands for the methodology design. It was especially challenging to find proper outcome indicators that would enable cross-site comparisons, in a way that attribution to the support can be made plausible, and wherein the diversity in contextmechanisms-outcome configurations could be 'captured' in typologies serving as learning material on good practices.

Table 2. Evaluation questions and their main methodology challenges.

\begin{tabular}{llll} 
& $\begin{array}{lll}\text { Measuring outcome } \\
\text { patterns }\end{array}$ & $\begin{array}{l}\text { Attribution in open } \\
\text { systems }\end{array}$ & $\begin{array}{l}\text { Generalisation and social } \\
\text { embeddedness }\end{array}$ \\
Does it work? & ++ & ++ & + \\
How does it work? & + & ++ & + \\
Will it work elsewhere? & + & ++ & ++ \\
\hline
\end{tabular}




\section{Intervention theory}

The small-grant fund finances investments in processing equipment and related capacity building to organised groups that are already engaged in collective marketing activities. The fact that the beneficiaries build on distinct trajectories of organisational change, work in a wide range of economic sectors, and all propose to seize different niche-market business opportunities in highly dynamic and contested markets, poses huge challenges for the tools and methods proposed to identify and attribute impact. Figure 1 illustrates this diversity in extremis, typical for many value chain support interventions in the financial sphere. The two main requisites, of formal existence as a legal person having a minimum of two years of collective marketing experience, together with a lean and transparent fund management based on an impartial and knowledgeable analysis of the viability of the business plan submitted, are assumed to be sufficient guarantee that the small grant can really make a difference in the organisations. By generating or expanding the activities of processing of agricultural products both income and organisational capabilities of the organisation are expected to be enhanced by experiential learning. Increased organisational performance makes it possible to improve service delivery to members, which eventually translates into increased wellbeing. The impact logic of this intervention is summarised in the following result chain (Figure 2).

\section{Key evaluation questions}

Based on evidence of impact, the fund expects to attract new and major donors to FONDOECAS and/or to induce the government or donors to replicate or upscale this lean and transparent small-grant allocation model for smallholder farmers' economic organisations. The core evaluation question in the assignment is: For what kind of organisations in what kind of contexts does a small-

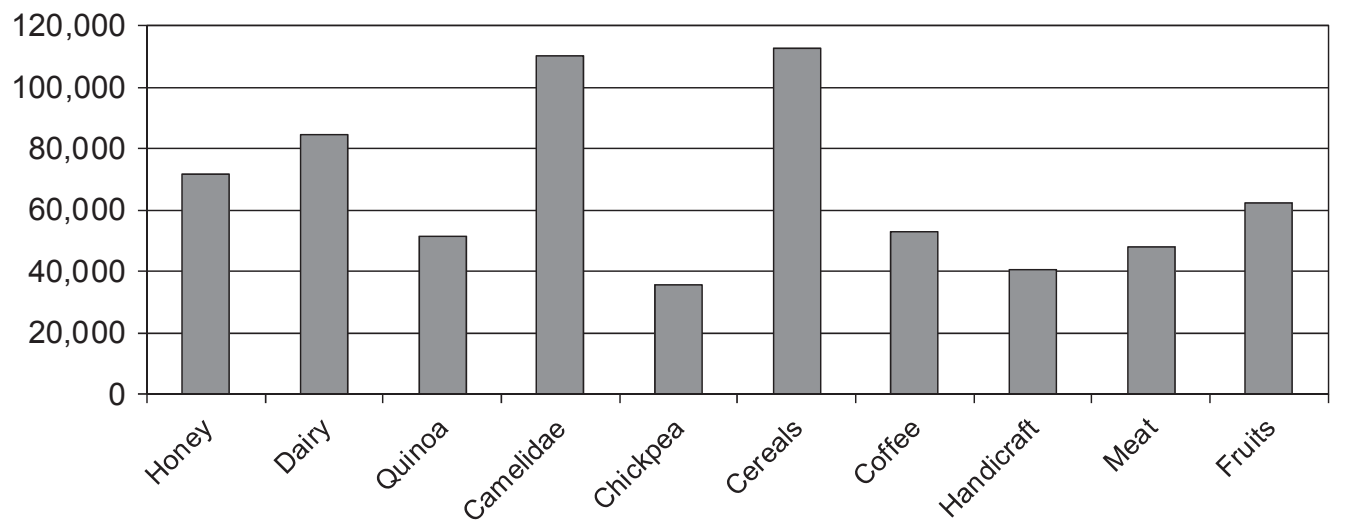

Figure 1. Distribution of FONDOECAS small grants among different sectors (period 2007-2010, in US\$).

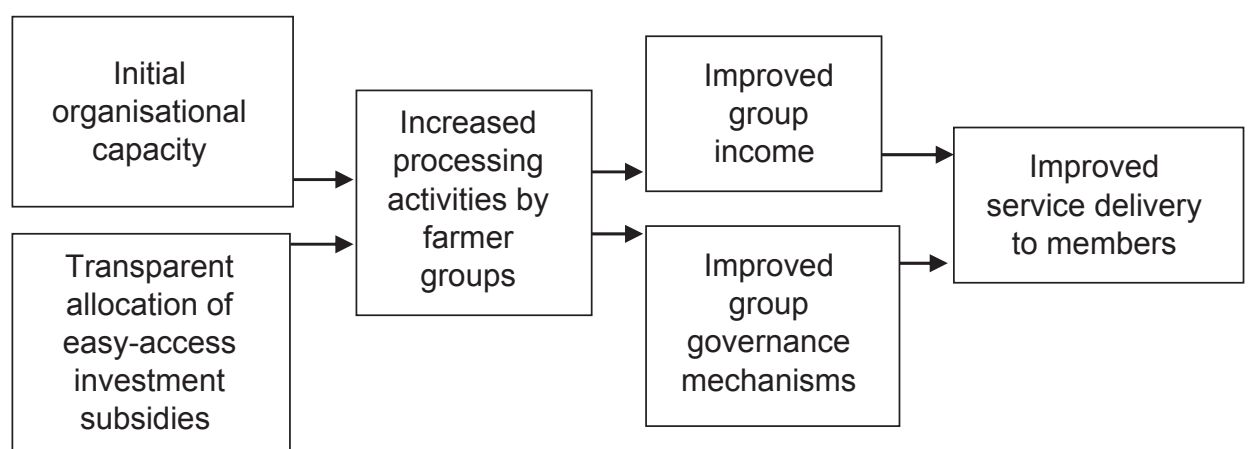

$\longrightarrow$ Is expected to lead to

Figure 2. Impact logic of the FONDOECAS small-grants fund. 
grant result in positive outcomes in the economic and organisational sphere? Therefore, the conclusions from the evaluation assignment are expected to respond especially to the third question: Will it work elsewhere? Attribution and generalisation are the key methodology challenges that needed priority attention when deciding on the core methodology, next to the inevitable measurement challenge.

\section{Core methodology}

To cover the major threats to validity related to the attribution issue, especially the issue of internal validity of the evaluative conclusion on impact, a quasi-experimental difference-in-difference design was chosen as the core methodology. Difference-in-difference implies a comparison between a baseline and a future situation for a group of fund beneficiaries (the treated) and a comparison group. The comparison group can be used for counterfactual reasoning: What would have happened to the organisations without the small grant? As a second step, the evaluation design team explored major threats to validity of the expected evaluative conclusion that would derive from this core methodology and related measurement methods, and added methods as part of a mixed method design. Table 3 summarises this exercise. The design embraces the notion of diversity in contexts and development trajectories, and collects information on a range of context variables, especially the mechanisms that are active in the baseline situation.

\section{Measurement challenge}

As an indicator of outcomes in the organisational capacities of the farmers' organisations, the evaluators decided to focus on the organisational capacities to contain the disintegrative mechanisms in collective action, so-called agency dilemmas (Cornforth, 2004; Olson, 1965; Ostrom, 2009). This was done, as, in spite of all diversity, these agency dilemmas prove to be 'inherent' in most collective marketing experiences, especially when they mature and scale-up (Bijman et al., 2011; Borgen, 2004; Cook, 1994; Ton, 2008). Therefore, time-series data on economic and organisational variables and a before-after assessment of the capacities of the organisations through a panel scoring exercise became key elements of the design. This resulted in a research tool to map the pertinence of common agency dilemmas, or disintegrative tendencies in collective

Table 3. Threats to validities to the core methodological design.

Type of validity Main threat threat

Statistical

Selection bias between treatment and comparison group

Internal

Attribution in
complex systems

Construct

$$
\begin{aligned}
& \text { Measurement of } \\
& \text { organisational } \\
& \text { capabilities }
\end{aligned}
$$

External
Additional mixed methods

Case-based statistics to maintain case integrity in group comparisons

Process tracing based on case descriptions of significant experiences in resolving agency dilemmas in collective action

Repetition of measurement with differing panel composition in the same organisation

Diversity in extremis Structured case studies, with due attention to incentive structures (internal organisational mechanisms) that limit opportunistic behaviour
Result/observation

Instead of measuring and comparing average impacts, we proposed to identify types of responses related to types of contexts and types of constellation of factors. These typologies will be refined and validated in focus group discussions with key stakeholders.

Evidence on the ways that organisations change their organisational capabilities by collective marketing activities will be collected, to test the specific 'intervention theory' that assumes that the agroprocessing experience translates into learning and generates refined internal regulations and incentive structures.

For each agency dilemma a description of the related incentive structure will be made. A panel survey is applied to map the agency dilemmas that prove 'problematic' in the daily operation of the organisation.

By focusing on behavioural incentives for internal control instead of functional diversity in economic activities, common challenges of organisations will be explored and solutions presented with a defined generalisation domain (CMO configurations) 
marketing, summarised in Table 4 . The research produced descriptions of the way that each organisation had learned to cope with these dilemmas and how this became codified and institutionalised in internal regulations and dispute settlement procedures. As farmers' organisations are expected to adjust and improve their internal organisation as a result of new business experiences, the baseline situation will compare these organisational capacities with the situation after the new business plan has been put in practice.

\section{Attribution challenge}

Each small grant (around US\$10,000) was part of a configuration of factors leading to an impact. A whole range of actors and factors were active in each organisation, all contributing to the outcomes of a specific business strategy of each farmers' organisation and often complementing other co-investments, generally by NGOs or local governments. The grant and related business plans were sometimes of a size and scope that only fit a particular village or subgroup within the organisation, while the major economic activities of the organisation remained relatively untouched (e.g. tourism as a complement to coffee exports; product development for indigenous handicrafts; cheesemaking equipment for rejected deliveries to the dairy processor, etc.).

The funded processing activities were very much related to the characteristics of the commodity/product (Figure 2) and its place in the members' agricultural system (e.g. dairy as a full time activity or honey as a complementary activity; coffee roasting or tourism development). This 'diversity in extremis' poses strong validity threats to the expected claims of attribution and impact; different configurations of factors

Table 4. Disintegrative tendencies in collective marketing (Ton, 2010).

‘Regulating member supply'

‘Quality assurance systems'

'Coping with working capital constraints'

'Anticipating side-selling'

‘Ways to dispose of profits'

‘Differentiating services to members and non-members'

‘Decision making on activities that benefit only a subgroup'

‘Task delegation and supervision of professional staff'

‘Disclosure of market information'

'Liability in contracts and loans'

‘Managing political aspirations'
Tensions can emerge when individual members increase their supply to the marketing organisation, and, in doing so, negatively affect the possibilities of other members to supply.

When a deal is made, the quality that the organisation has promised will have to be controlled for: individual members may tend to deposit lower quality and the organisation needs a system to maintain minimum quality requirements.

Many smallholder farmers tend to face cash constraints and ask for fast payment, while the organisation needs time to finish transactions with the ultimate buyer.

The organisation might provide a credit service or advance payment system to enable production. However, there is a serious risk that farmers 'side-sell' their product to competing traders or processors, to which they have no repayment obligation.

When the organisation makes a profit, it will tend to invest or increase capital reserves, while the member will have a tendency to prefer more short-term benefits, e.g. better prices.

Most economic organisations need contributions from members to realise their business opportunities. However, members face a number of disincentives to do so when benefits which flow from investment accrue to investors and non-investors alike.

When the type of investment is not likely to benefit all members, investment decisions that seem economically optimal from the perspective of the management are not necessarily desirable from the standpoint of (sub-groups of) members.

Member-based organisations elect persons to supervise and support the management. However, the limited technical knowledge of board members and the lack of transparency of information disclosed by the management often limit the effectiveness of this governing structure.

Investments in market intelligence become an asset for the bearers of it, usually the sales persons. The group has to decide on partial or full disclosure of market information, motivating group investment in market intelligence and preventing defection of personnel.

There is an inherent tension between members who want to limit their liability for group actions and the need of the group as a whole to generate as much collateral as possible. Organisations specify procedures for decision making when the board is contracting on behalf of the group.

Economic smallholders' organisations tend to take up a broader representative role next to their economic service provisioning to members. Members delegate their political voice to the organisation while the political representatives of the organisation may never fully discuss all political decisions with them. 
(size, networks, degree of professionalisation, level of trust, etc.) might lead to positive impacts in certain contexts/ sectors/activities and fail in others.

Therefore, the evaluation proposed a comparative case study design that could generate structured information to be analysed with configurational comparative methods (Byrne and Ragin, 2009; Rihoux and Ragin, 2008), a wide term that covers a range of statistical procedures that look for causality/attribution between configurations of factors and outcome indicators in case observations. This is in contrast or complementary to mainstream testing of differences on discrete variables through regression-based econometrics.

\section{Generalisation challenge}

To maximise the generalisation domain, we selected a random sample of 30 organisations from the ones that received a grant from FONDOECAS. Additionally, we selected randomly a comparison group of 20 organisations that could have applied but did not (yet), having similar characteristics, especially having a legal personality.

To enable the distillation of 'good practices' in collective marketing organisations, with a defined generalisation domain, we designed a simple comparative case study format to take stock of key organisational learning experiences on ways to resolve these agency dilemmas (Table 5). These 'thick descriptions' complement the time-series data and panel scoring, and help to underpin the basic assumption in the intervention theory that the supported economic practices induce learning on the management of collective action problems.

\section{Conclusions: towards a theory-based mixed methods design}

This paper contributes to efforts enhancing the capacity to demonstrate development impacts of value chain support. This issue receives high priority by donor organisations and development practitioners and has translated into increasingly standardised and rigorous impact assessments to demonstrate the relevance of their work and to learn from interventions and pilots. The paper builds on the distinction of three types of evaluative questions and four threats to validity to evaluative conclusions in order to address the key methodological challenges in impact evaluation of agricultural value chain support. This discussion translates into three major methodological challenges: measuring outcome patterns, attribution in open systems, generalisation of socially embedded interventions.

The paper suggests shifting attention to explicit, ex-ante theorisation (Donaldson et al., 2008; Pawson, 2003; Rogers, 2009). In statistical analysis of data-set observation on change processes, theorisation feeds the selection of variables in the regressions and, eventually, the matching process used to compare the treated and the untreated. In case studies of project pilots, theorisation in the realist tradition explicates the inner workings of mechanisms triggered by the intervention. In prospective discussion on replicability or scalability of value chain interventions or pilots, ex-ante theorisation identifies contextual requirements for intervention mechanisms to be triggered as well as outcome indicators or proxies that are measurable or observable if the intervention works.

Table 5. Concise format for comparative case-study interviews.

\begin{tabular}{l}
\hline Context \\
Description of the problem that occurred \\
Time and place it occurred \\
Involved stakeholders \\
Contributing factors \\
Pallet of options \\
The main options discussed at that time envisaged to solve the problem \\
Internal decision making process \\
External influence on decision making process \\
Incentive structure introduced \\
Internal arrangement chosen: what did they decide to do and how was it expected to be effective? \\
How has it been formalised and communicated to the members? \\
How has it worked out in practice? \\
What effect did it have: organisational, economically, socially? \\
Do they recommend the solution to other organisations? \\
If so, what would most likely be adjusted to the new context? \\
If not, what alternative solution do they suggest? \\
Recommendation
\end{tabular}


The paper applies the methodological discussion in the case of a small grant facility adopted by a variety of farmers' organisations active in different value chains. It uses a realist orientation for documenting 'good practices' or promising 'principles' with the purpose to draw conclusions for replication of the intervention in a comparable context with a similar configuration of conditions. Information to conclude on comparability of two configurations (the match between the case-study reality and the reality in the new intervention context) will always be incomplete, but the realist question 'What works for whom under what conditions?', is helpful to generate information that detects good practices in their contexts.

The application confirms that multiple methods are needed to support evaluative conclusions. An appropriate mix of methods will have to respond to the specific mix of evaluative questions and the 'kind of conclusion' that the stakeholders inducing the evaluation are expecting from the assignment. The concept of threats to validity developed by Shadish et al. (2002) is useful to check the design of the mix of methods. Starting from the core methods of collecting information, the review of the threats to validity in its four dimensions (statistical conclusion validity, internal validity, construct validity and external validity) may indicate the need for additional research methods to underpin conclusions and particularly to respond to the quest from practice and policy to conclude on the replicability of value chain support to new contexts with different conditions. Impact evaluation demands serious efforts from organisations to invest in critical reasoning while designing interventions, presenting an initial 'intervention theory' or 'impact logic' that can be tested and improved through monitoring and evaluation activities. Using a realist method to describe and analyse intervention pilots as comparative case studies will facilitate the exchange of experiences between development agencies. Its inherent restricted and defined generalisation domain may prevent uncritical embracement of good practices. For example, specific types of contract farming, branding, fair trade labelling prove to be viable and effective in a wide range of situations but are not the panacea, the standard solution, for achieving development impacts by value chain support.

\section{Acknowledgements}

This paper is a result of the research programme Value Chains for Pro-poor Development (VC4PD) implemented under the Partnership Programme 'Globalisation and Sustainable Rural Development' between the Netherlands' Ministry of Foreign Affairs and Wageningen UR and of the Knowledge Base Funds of the Netherlands Ministry of Economic Affairs, Agriculture and Innovation (project KB-
03-008-004 in the programme Chains and Logistics). The authors would like to thank the anonymous referees of the Journal of Chain and Network Science for their comments to improve this paper.

\section{References}

Bamberger, M., 2007. Simply the best? understanding the market for 'Good Practice' advice from government research and evaluations: a framework for assessing validity and utilization of evaluations. American Evaluation Association, Baltimore, MD, USA.

Bamberger, M., J. Rugh and L. Mabry, 2006. RealWorld evaluation: working under budget, time, data, and political constraints, Sage Publications, Thousand Oaks, CA, USA.

Begg, C., 1994. Publication bias. The Handbook of Research Synthesis, Russell Sage Foundation, New York, NY, USA, 399-409.

Bijman, J., R. Muradian and A. Cechin, 2011. Agricultural cooperatives and value chain coordination. In: Helmsing, A.H.J. and S. Vellema (eds.) Value chains, inclusion and endogenous development: contrasting theories and realities. Routledge, New York, NY, USA.

Blaikie, N.W.H., 1991. A critique of the use of triangulation in social research. Quality and Quantity, 25: 115-136.

Blaikie, N.W.H., 2000. Designing social research: The logic of anticipation, Polity Press, Cambridge, UK.

Blatter, J. and T. Blume, 2008. In search of co-variance, causal mechanisms or congruence? Towards a plural understanding of case studies. Swiss Political Science Review, 14: 315-356.

Borgen, S.O., 2004. Rethinking incentive problems in cooperative organizations. Journal of Socio-Economics, 33: 383-393.

Brady, H.E., D. Collier and J. Seawright, 2006. Toward a pluralistic vision of methodology. Political Analysis, 14: 353-368.

Byrne, D. and C. Ragin, 2009. The SAGE Handbook of Case-Based Methods, Sage Publications, Thousand Oaks, CA, USA.

Chelimsky, E. and W.R. Shadish, 1997. Evaluation for the 21st century: a handbook. Sage Publications, Thousand Oaks, CA, USA.

Chen, H.T., 1994. Theory-Driven Evaluations, Sage Publications, Thousand Oaks, CA, USA.

Cook, M., 1994. The role of management behavior in agricultural cooperatives. Journal of Agricultural Cooperation, 9: 42-58.

Cornforth, C., 2004. The Governance of cooperatives and mutual associations: a paradox perspective. Annals of Public \& Cooperative Economics, 75: 11-32.

Creevey, L. and M. Ndiaye, 2008. Common problems in impact assessment research. Impact Assessment Primer Series \#7, USAID, Washington DC, USA.

Creevey, L. and G. Woller, 2006. Methodological issues in conducting impact assessments of private sector development programs. Impact Assessment Primer Series \#2, USAID, Washington DC, USA. 
DAC, 2008. Evaluating development co-operation: summary of key norms and standards, OECD, Paris, France.

DCED, 2010. The DCED standard for measuring achievements in private sector development: control points and compliance criteria. Version V., Donor Committee for Enterprise Development, Cambridge, UK. Available online at: http://www.enterprisedevelopment.org/page/measuring-and-reporting-results.

Denzin, N.K., 1970. The research act. Aldine Transaction, London, UK.

Donaldson, S., C. Christie and M. Mark, 2008. What counts as credible evidence in applied research and evaluation practice?, Sage Publications, Thousand Oaks, CA, USA.

Duflo, E., R. Glennerster, M. Kremer, L. Center and T. Floor, 2007. Chapter 61 Using randomization in development economics research: a toolkit. In: Schultz, T.P. and J.A. Strauss (eds.), Handbook of development economics, volume 4, Elsevier, Amsterdam, the Netherlands, p. 3895-3962.

European Commission, 2008. Second Strategic Review of Better Regulation in the European Union European Commission, Brussels, Belgium.

Farrington, D.P., 2003. Methodological quality standards for evaluation research. The ANNALS of the American Academy of Political and Social Science, 587: 49-68.

Gerring, J., 2008. The mechanismic worldview: thinking inside the box. British Journal of Political Science, 38: 161-179.

Heckman, J.J., 2005. The scientific model of causality. Sociological Methodology, 35: 1-98.

Heckman, J.J. and J.A. Smith, 1995. Assessing the case for social experiments. The Journal of Economic Perspectives, 9: 85-110.

Helmsing, A.H.J. and S. Vellema, 2011. Value chains, inclusion and endogenous development: contrasting theories and realities, Routledge, New York, NY, USA.

Hospes, O., 2008. Evaluation evolution?- three approaches to evaluation. The Broker, 2008: 24-26.

Humphrey, J. and L. Navas-Aleman, 2009. Multinational value chains, small and medium enterprises, and 'pro-poor' policies: a review of donor practice. IDS Research Report 63, IDS, Brighton, UK.

Khandker, S., B. Koolwal and H. Samad, 2009. Handbook on impact evaluation. World Bank, Washington DC, USA, 239 pp.

Lawson, T., 2003. Reorienting Economics, Routledge, New York, NY, USA.

Lawson, T., 2009. Applied economics, contrast explanation and asymmetric information. Cambridge Journal of Economics, 33: 405-419.

Mackie, J.L., 1965. Causes and conditions. American philosophical quarterly, 245-264.

Maredia, M.K., 2009. Improving the proof: evolution of and emerging trends in impact assessment methods and approaches in agricultural development, IFPRI Discussion Paper 00929. IFPRI, Washington DC, USA..
Mill, J.S.S., 2009 (1843). System of logic ratiocinative and inductive: being a connected view of the principles of evidence and the methods of scientific investigation. Cosimo Classics, New York, NY, USA.

Olson, M., 1965. The logic of collective action: public goods and the theory of groups. Harvard University Press, Cambridge, MA, USA..

Ostrom, E., 2009. Building trust to solve commons dilemmas: taking small steps to test an evolving theory of collective action. In: Leven, A.S. (ed.), Games, Groups, and the Global Good. Springer-Verlag, Heidelberg, Germany, p. 207-228.

Pawson, R., 2002. Evidence-based Policy: The promise of 'realist synthesis'. Evaluation, 8: 340-358.

Pawson, R., 2003. Nothing as practical as a good theory. Evaluation, 9: 471-490.

Pawson, R. and N. Tilley, 1997. Realistic evaluation, Sage Publications, Thousand Oaks, CA, USA.

Ragin, C., 2000. Fuzzy-set social science. University of Chicago Press, Chicago, IL, USA.

Ragin, C., 2008. Redesigning social inquiry: fuzzy sets and beyond. University of Chicago Press, Chicago, IL, USA.

Ravallion, M., 2009. Should the Randomistas Rule? The Economists' Voice, 6: 6 .

Rihoux, B. and C. Ragin, 2008. Configurational comparative methods. Qualitative Comparative Analysis (QCA) and related techniques (Applied Social Research Methods). Sage, Thousand Oaks, CA, USA.

Roche, C.J.R. and C. Roche, 1999. Impact assessment for development agencies: learning to value change. Oxfam-NOVIB, London, UK.

Rogers, P.J., 2009. Matching impact evaluation design to the nature of the intervention and the purpose of the evaluation. Journal of Development Effectiveness, 1: 217-226.

Shadish, W.R., T.D. Cook and D.T. Campbell, 2002. Experimental and quasi-experimental designs for generalized causal inference. Houghton Mifflin Co. Boston, MA, USA.

Snodgrass, D., 2006. Assessing the impact of new generation private sector development programs. Impact Assessment Primer Series \#1, USAID, Washington DC, USA.

Snowden, D. and M. Boone, 2007. A leader's framework for decision making. Harvard Business Review, 85: 68.

Tanburn, J., 2008. The 2008 reader on private sector development: measuring and reporting results. International Training Centre ILO, Turin, Italy.

Ton, G., 2008. Challenges for smallholder market access: a review of literature on institutional arrangements in collective marketing. Stewart Postharvest Review, 4: 1-6.

Ton, G., 2010. Resolving the Challenges Of Collective Marketing: incentive structures that reduce the tensions between members and their group. ESFIM Policy Brief \#4, ESFIM, Wageningen, the Netherlands. 
Ton, G., S. Taylor, J. Vlaming and S.R.C.H. Hiller, 2010. Evaluating poverty impacts of bottom-of-the-pyramid irrigation technology supply: IDE's rolling baseline approach to household income impact assessment. AEA Annual Conference 'Evaluation 2009: Context and Evaluation'. November 11-14. Orlando, Florida. Available online: http://tinyurl.com/69gdhpg.

Vaessen, J., 2010. Methodological and conceptual challenges in evaluating the impact of development interventions. Datawyse / Universitaire Pers Maastricht, Maastricht, the Netherlands.

Vellema, S., 2011. Transformation and sustainability in agriculture: connecting practice with social theory, Wageningen Academic Publishers, Wageningen, the Netherlands.

World Bank, 2007. World development report 2008: agriculture for development, World Bank, Washington DC, USA.

Zandniapur, L., J. Sebstad and D. Snodgrass, 2004. Review of evaluations of selected enterprise development projects. MicroREPORT \#3, USAID, Washington DC, USA. 